\title{
Driving decarbonisation of the EU building stock by enhancing a consumer centred and locally based circular renovation process
}

\author{
Ana Tisov ${ }^{1}$, Kalle Kuusk ${ }^{2}$, Miriam Navarro Escudero ${ }^{3}$, Margarita Niki Assimakopoulos ${ }^{4}$, Dimitra Papadaki ${ }^{4}$, Peep \\ Pihelo' , Peter op 't Veld', Targo Kalamees ${ }^{2}$ \\ ${ }^{1}$ Huygen Installatie Adviseurs, Netherlands \\ ${ }^{2}$ Tallinn University of Technology, Estonia \\ ${ }^{3}$ Instituto Valenciano de la Edificación, Spain \\ ${ }^{4}$ University of Athens, Greece
}

\begin{abstract}
H2020 project DRIVE0 (Driving decarbonisation of the EU building stock by enhancing a consumer centred and locally based circular renovation process) aims to come to a decarbonisation of the EU building stock and to accelerate deep renovation processes by enhancing a consumer centred circular renovation process in order to make deep renovation more attractive for consumers and investors, more environmental friendly. Circular renovation concepts and process will specifically be developed and implemented in the seven demonstration cases in seven countries, representing all climatic zones in Europe
\end{abstract}

\section{Introduction}

Decarbonisation of the EU building stock is one of the most important and complex target in EU [1] to achieve a decarbonized European society in general. While the built environment is responsible for $40 \%$ of final energy consumption in the EU, embodied energy in buildings accounts for up to $60 \%$ of the building's life cycle energy, with collateral embodied $\mathrm{CO}_{2}$. Within the EU more than $50 \%$ of all extracted materials are attributed to buildings. The exploitation of natural resources and its collateral environmental impact is a serious threat to the natural, social and economic systems in the EU. Renewable energy technologies as well as reuse and recycling of resources/materials are needed to overcome this challenge. Therefore, a transition to both a deep and circular renovation of the total European building stock is necessary to meet the challenge of decarbonisation.

One of the most important lessons learned from the 'first generation' pilot projects on deep renovation is that the main barriers are not related to specific technical solutions [2,3], cost effectiveness [4,5], but deal with the deep renovation and nZEB knowledge, for both the building owners/users [6] and for the designers [7]. Although the need for multiple benefits of improved energy efficiency, by a holistic approach (i.e. combining energy efficiency with improved indoor environmental quality, health and wellbeing, improving moisture safety) are very well known [8,9], these are not yet fully integrated in consumer centred business models, necessary to achieve higher rates of renovation to decarbonize the building stock in order to meet longterm climate, environmental and energy targets.

Over the last years, a number of relevant projects have addressed several of these aspects in a comprehensive way, both in developing technological solutions (to a TRL 6 to 7) [10-12], addressing and solving market barriers and strategies for involving endusers [13]. The next step toward sustainable renovation is to take into account embodied aspects such as embodied energy and embodied $\mathrm{CO}_{2}$. Raising awareness and good demonstrations are needed to guide apartment associations to order new solutions [14]. After the renovation process designers, constructors, and endusers should have access to data on the real total building performance in practice, both on energy, indoor environmental quality, moisture safety, and especially health and well-being in relation to the renovation. Without this information performance gap between designed and realized targets for the higher performance building may remain too big [15-17].

DRIVE 0 will use a circular deep renovation, which contributes to a circular built environment, is based on $100 \%$ life cycle renewable energy, and all materials used within the system boundaries are part of infinite technical or biological cycles with lowest quality loss as possible. DRIVE 0 will build upon these results by combining these outcomes, redevelop the most successful solutions to holistic circular concepts with a TRL 8 to 9, and make these applicable in practice to endusers by consumer centred business models. 


\section{Methods}

\subsection{Attractive, environmentally friendly, faster and cost effective deep renovation processes}

We will use developing proven plug \& play prefab deep renovation solutions for building elements and building services a step further towards holistic circular renovation products and concepts. In several H2020 projects on deep renovation these plug \& play prefab solutions for renovation of the building envelope and building services have been developed and tested, in most of the cases to a TRL of 6 to 7. These renovation concepts are mainly based on improving the operational energy performance of buildings (and not yet on embodied energy). These prefab plug \& play solutions have proven to be effective solutions to come to a substantial:

- Reduction of both renovation time on site and costs.

- Reduction of disturbance for occupants during the renovation works.

- Quality improvement by better quality control during the production process (then on-site works).

The most promising solutions will be developed further to circular renovation products (re-use and recycling of materials, bio-based materials) and bring these products to a market ready level with a TRL of 8-9. The products to be developed further will be:

- Prefab plug \& play solutions for facades, roofs, and additional modules, both 2D as 3D1.

- Prefab platforms for building services.

- Smart building and installation details for mounting and de-mounting, ensuring quality during life-time and re-usability.

These products will be prefab produced in fully automated BIM controlled productions lines in order to enhance quality and to reduce costs.

\subsection{Understandable information of real total life- cycle performances to consumers and potential investors of deep renovation projects}

The circular renovation concepts will be made both more attractive and more reliable to consumer/end-users (meant also as potential investors) by providing attractive and understandable information of the total life-cycle performances of their renovated homes.

These 'total performances' include the monitoring of physical parameters related to the indoor environment itself, such as energy and IEQ, but also other indicators that assess the experience of building occupants, such as, well-being and health. This technical data will be translated into understandable information for building occupants including guidance and tips, as well as insight in the material flows in a circular system.

Existing platforms will be customized and implemented in the demonstration cases: the DRIVE 0 platform. Specifically, DRIVE 0 will focus on communication to end-users:

- How to come from big data to smart data, understandable for consumers and investors?
- How to account for social learning effects?

- How to frame Drive 0 to inform and persuade occupants, end-users and investors to invest in circular renovations?

- How to train occupants to change behaviour and become more sustainable?

\subsection{Design and realization of circular renovation solutions}

One of the key questions that will be solved is: how the design process will look like in order to design and engineer deep renovations solutions from these local materials, taking into account different material cascades; re-use, re-process and re-cycle. This work will lead to the creation of a "EU Circular Renovation Atlas", considering environmental aspects, local based geomaterials, surplus materials from deconstruction sites, available construction technologies and their possible variation in the different studied areas.

DRIVE 0 addresses the following local drivers:

- National policy and obligations to make buildings 'natural gas-free', i.e. disconnecting from the gas grid

- Combined structural/seismic renovation in seismic areas

- Redevelopment of 'medianeras', typical blind facades, in many European cities

- Redevelopment of abandoned industrial sites with local variable materials from (partly) demolition

- Local policy of mandatory circular/C2C renovation

- Redevelopment of deprived area's (social housing) The realization of circular renovation will:

- Give input for the assessment of the potential of local available reusable materials, discriminating local drivers and relevant local stakeholders in the total local value chain.

- Give feedback on the practical working and usefulness of the proposed consumers centred circular renovation concepts (performance in practice, actual renovation time, the extent to which materials are actually re-used, the extent of appreciation by end-users etc.).

- Providing evidence to the involved end-users and to the most important stakeholders on EU level (such as European 'umbrella organisations' and interest groups).

- Provide input for a comparison of the potentials and effectiveness of using and exploiting local drivers. Local policy of mandatory circular/C2C renovation.

\subsection{New consumer centred business models for circular renovation concepts}

New consumer centred circular business models, supported by the use of existing financial mechanisms, instruments and decision tools, in combination with economic attractive circular renovation products to enhance success for circular renovation concepts in the market will be devised. The objective will aim at:

- Promoting the circular renovation concepts and products as attractive products, both in performances as in price. 
- Promoting material banks in collaboration with organizations.

- Encouraging participation of end-users and investors in circular deep renovation projects, making them full responsible actors.

- Providing potential investors with reliable information of possibilities and opportunities of potential circular deep renovation solutions. A net present value analysis will be performed taking into account the cash flows over the lifetime of the technology packages in combination with innovative business models (e.g. product as a service, leasing).

The business models will be compatible and will be developed as modules, ready to be plugged in with platforms as being developed in some other H2020 project. These existing models will be further developed and optimized in the DRIVE 0 approach. The business models will be connected to the existing platform ad will be implemented to maximise the levels of legitimacy in order to generate a strong confidence on participants and investors in their ability to shape deep renovation project results.

\section{Results}

\subsection{Live study and demonstration cases}

Seven live study and demonstration cases, in seven countries, representing all climatic zones in Europe, will demonstrate the working of validated and evidence based operational DRIVE 0 holistic circular renovation packages and supporting business models

\subsubsection{Circular neighborhood, the Netherlands}

In the Dutch case, building upon state-of-the-art modular and plug-and-play (nZEB) retrofit technologies, a circular deep-renovation demonstrator will be completed. The demonstration project includes typical Dutch terraced housing owned by a social housing associations. The circular deep-renovation of the Dutch demonstrator focusses on refurbishing the envelope with prefabricated modules and installing a building services 'engine'.

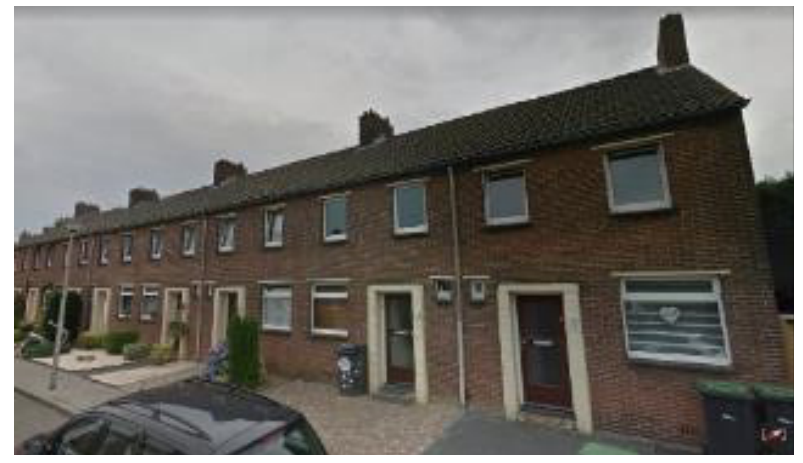

Fig 1. The terraced dwelling in the Netherlands.

Case specific outcomes:
- a realized life cycle zero energy circular retrofit of an existing terraced dwelling typology common in the Netherlands based on the concept of urban mining with maximum locally re-used and recycled materials and locally based bio-based materials;

- a deep renovation concept with an expected investment per dwelling of 50 kEuro;

- high energy performance in the renovated buildings resulting in an energy consumption of $15 \mathrm{kWh} /\left(\mathrm{m}^{2} \mathrm{a}\right)$;

- a cost reduction of $25-50 \%$ compared to current deep renovation strategies, based on a high level of prefabrication using locally mined existing materials.

\subsubsection{Medianeras, Spain}

There is a high replication potential in the European building stock for the renovation of the so-called "medianeras" - bind walls that separate two different buildings and are opaque because there is traditionally a possibility that the neighbouring building will be constructed higher, so there is no prevision that the wall will stay visible. However, there are locations where no new or higher construction is possible anymore due to the urban planning regulations change, occasionally combined with demolition of the neighbouring buildings, so the medianera walls stay permanently uncovered.
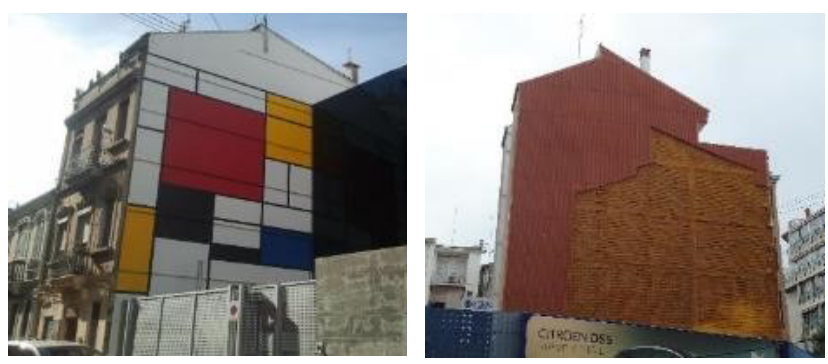

Fig 2 Examples of typical states of the medianera walls in Spain.

Case specific outcomes:

- reduction of the embodied energy;

- training of the local actors, acquiring skills necessary for design, manufacturing, installation and maintenance of systems based on circular principles;

- energy performance improvement resulting in an energy consumption of $15 \mathrm{kWh} /\left(\mathrm{m}^{2} \mathrm{a}\right)$;

- overall life cycle cost reduction of $25-30 \%$ compared to current deep renovation strategies, based on a high level of prefabrication using local materials;

- reduction of time needed on site for renovation works, due to the prefabrication off-site techniques, allowing minimized user disruption.

\subsubsection{Private residences, Ireland}

The case study is a typical Irish terraced house made of bricks. The private dwelling is located in the extended Dublin area and it was built in the 30's. Private owners can benefit from this "good practice" example improving and fostering circular renovation. The reconstruction of 
unused or uncomfortable spaces makes it possible to implement new volumetric additions.

Case specific outcomes:

- a systematic urban renovation at a neighbourhood level, minimizing occupants' discomfort, increasing industrialization of the components needed for the energy retrofit;

- a significant increase of the real estate value and a shortening of payback time of renovation, representing also an opportunity for local construction companies who can foster this type of strategy;

- after renovation $78 \%$ of primary energy saving and $80 \% \mathrm{CO}_{2}$ emissions reduction.

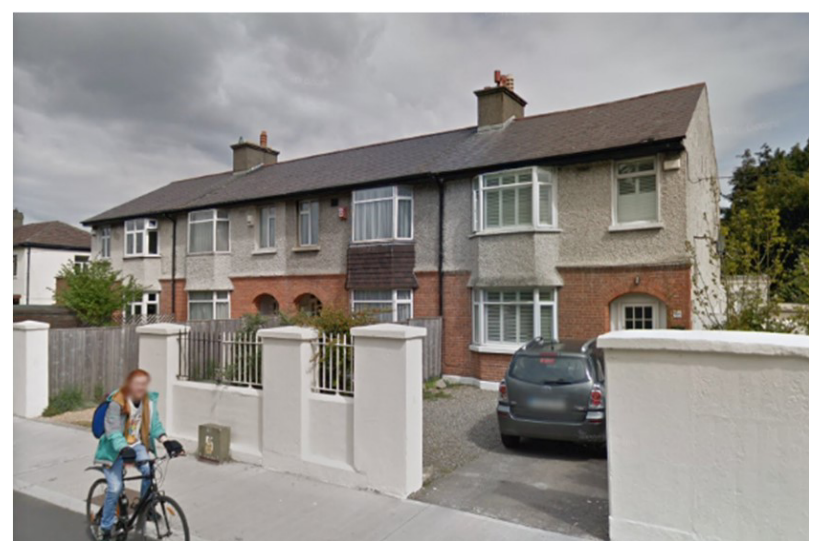

Fig 3. Private residences in Ireland.

\subsubsection{Abandoned manor, Italy}

The abandoned agricultural building stock has a very strong potential, especially for social purposes.

The villa consists of two floors for a total of 14 rooms and two bathrooms, at the ground floor of the barn there is a porch and a big space that are optimal for a future public use. The typical rural architectural aspect makes this case study an exceptional example of territorial architecture.

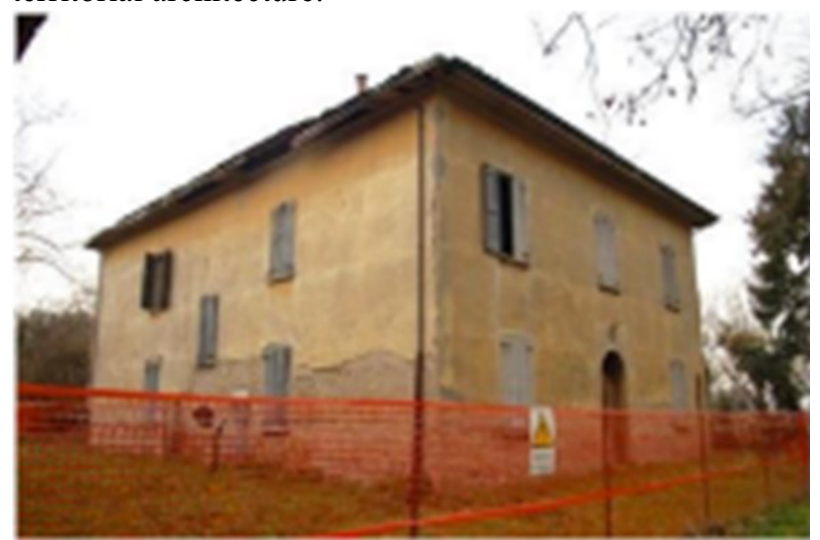

Fig 4. The abandoned manor in Italy.

Case specific outcomes:

- a circular deep retrofitted abandoned rural building as a demonstration of the concept;

- demonstration of the effectiveness and replicability of the proposed solutions to lead to an increased rate of renovation;
- a life cycle zero energy circular retrofit with maximum locally re-used and recycled materials and locally based bio-based materials;

- after renovation $70 \%$ of primary energy saving and $70 \% \mathrm{CO}_{2}$ emissions reduction.

\subsubsection{Apartment building, Estonia}

In Estonia, more than $70 \%$ of the residents live in apartment buildings, constructed before 1990. The majority of those buildings have the same typical problems: high energy consumption levels, insufficient ventilation, uneven indoor temperatures, and insufficient thermal comfort levels. Therefore, a pretty extensive, or 'deep' level of renovation is required.

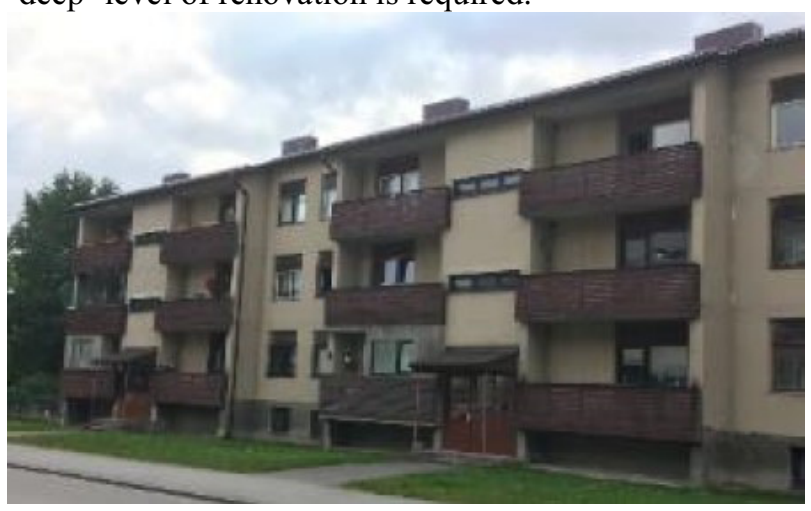

Fig 5. Apartment building in Estonia.

Case specific outcomes:

- deep energy renovation with prefabricated modules based bio-based material and building integrated technologies;

- improved living comfort and IEQ for the occupants achieved by means of the insulated building envelope, moisture safety control, and user-centric operation and management building systems;

- balanced ventilation with heat recovery where ventilation pipes are integrated into modular additional insulation elements;

- the bio-based heat source for heating and domestic hot water;

- the increase of renovation design accuracy, while reducing construction-associated risks supported by $3 \mathrm{D}$ scanning and geomatics technologies to reconstruct the actual geometry of the existing building.

\subsubsection{Single-family house, Slovenia}

There are roughly 524.000 residential buildings in Slovenia and vast majority - $89 \%$ represent single-family houses. Characteristics of houses are relatively large heated volumes, often with nonoptimal use of living space (large heated hallways, stairs, etc.), with very little or no thermal insulation, therefore resulting in large operating costs, often accompanied with mold problems.

Case specific outcomes:

- complete energy renovation, insulated by recyclable mineral wool; 
- improved quality of implementation as a measure for decreasing the gap between theory and practice;

- to test the possibilities for separation, sorting and direct recycling of the old mineral insulation materials in our production.

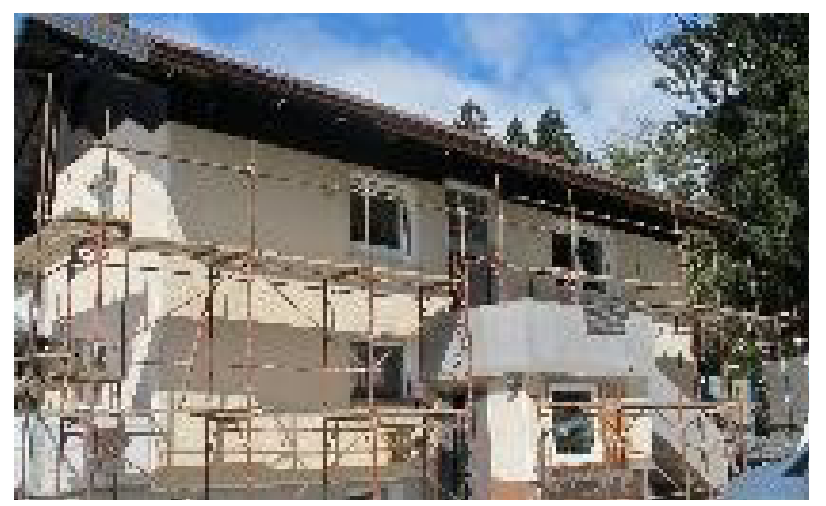

Fig 6. The abandoned manor in Italy.

\subsubsection{Residential apartment, Greece}

Most residents in Greece live in buildings constructed before 1990, with low energy performance factors such as high energy use levels, insufficient ventilation, uneven indoor temperatures, and insufficient thermal comfort levels. Therefore, a deep level of renovation is required.

Given the fact that most of the buildings are privately owned and located in urban areas it is almost impossible (due to the excessive bureaucracy) and very expensive solution to reconstruct new buildings. A major renovation of the existing buildings would be the only practical, cost- effective and low-energy solution.

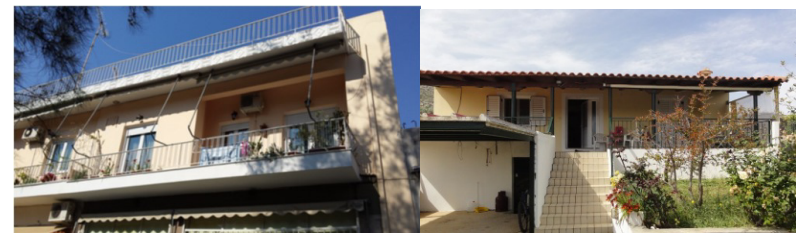

Fig 7. Two case studies in Greece.

Case specific outcomes:

- an integrated thermal insulation system by solutions for facades, roofs;

- new high-quality heating system

Installation of Photovoltaic's

- air conditioning and ventilation systems.

- after renovation $60 \%$ of primary energy saving and $37 \% \mathrm{CO}_{2}$ emissions reduction.

\subsection{Primary energy savings}

DRIVE 0 will directly trigger for energy savings and renewable energy by the deep renovation in three layers:

- The first layer is the existing buildings in the seven small scale demonstration cases (units), representing a total of $3944 \mathrm{~m} 2$ deep renovated floor area. As DRIVE 0 aims to demonstrate a new and disruptive approach for circular renovation there is deliberately chosen for small scale demonstrators but on a relatively large number of locations in Europe, in order to have a maximum spin off. The DRIVE 0 partners are directly connected with the stakeholders and decision makers in the pilots.

- The real impact on energy savings is achieved in the second layer. All these pilot projects are part of larger complexes or part of the building stock owned by the 'case holders', to be deep renovated during or directly after the project duration once the small-scale demonstrators (first layer) have given evidence of the performances. The impact on energy savings is enlarged in the Second layer: The replication potential directly triggered by the demonstration projects.

- Finally, a Third layer is introduced: the potential by multiplying the impact by the members of three European umbrella organizations, i.e. ACE, Housing Europe and UIPI and their national members are potential end-users, triggered by the promotion and awareness campaigns, in the second half of the project and after the project duration.

Table 1. The direct impact of the demonstration projects with energy performances

\begin{tabular}{|l|c|c|c|}
\hline Country & $\begin{array}{c}\text { Existing } \\
\text { energy use, } \\
\mathrm{kWh} /\left(\mathrm{m}^{2} \mathrm{a}\right)\end{array}$ & $\begin{array}{c}\text { Primary } \\
\text { energy } \\
\text { saving, } \%\end{array}$ & $\begin{array}{c}\text { Energy use } \\
\text { after renov., } \\
\mathrm{kWh} /\left(\mathrm{m}^{2} \mathrm{a}\right)\end{array}$ \\
\hline NL & 180 & 90 & 18 \\
\hline ES & 208 & 87 & 27 \\
\hline IR & 402 & 78 & 87 \\
\hline IT & 180 & 70 & 54 \\
\hline EE & 178 & 70 & 53 \\
\hline SI & 310 & 75 & 78 \\
\hline GR & 350 & 65 & 140 \\
\hline
\end{tabular}

Table 2. The replication potential directly triggered by the demonstration projects

\begin{tabular}{|l|c|c|c|}
\hline Country & $\begin{array}{c}\text { Additional } \\
\text { number of } \\
\text { units }\end{array}$ & $\begin{array}{c}\text { Additional } \\
\text { net floor } \\
\text { area, } \mathrm{m}^{2}\end{array}$ & $\begin{array}{c}\text { Additional } \\
\text { primary sa- } \\
\text { ving, GWh/y }\end{array}$ \\
\hline NL & 2000 & 180000 & 29 \\
\hline ES & 1400 & 112000 & 20 \\
\hline IR & 20 & 2200 & 1 \\
\hline IT & $2 / 8$ & $690 / 2460$ & $0.1 / 0,3$ \\
\hline EE & 1680 & 150000 & 18 \\
\hline SI & 90 & 15030 & 3 \\
\hline GR & 11 & 3000 & 1 \\
\hline Total & 5211 & 465380 & 73 \\
\hline
\end{tabular}

\subsection{Investments}

Depending on the renovation strategy and methods the investments for deep renovation for the building envelope and building services can vary from 650$850 € / \mathrm{m}^{2}$ for residential buildings. Current $\mathrm{H} 2020$ projects show that with prefab plug \& play technologies $€ 650 / \mathrm{m}^{2}$ is achievable (energy savings $70 \ldots 80 \%$ ); this figure can be roughly divided into $€ 350 / \mathrm{m}^{2}$ for 
'traditional' or 'anyway' renovation and $€ 300 / \mathrm{m}^{2}$ for the extra savings to $70 \ldots 80 \%$.

This means the following investments triggered:

- First layer: $3.943 \mathrm{~m}^{2}=€ 256 \mathrm{M}$

- Second layer: $465.380 \mathrm{~m}^{2}=€ 30250 \mathrm{M}$

- Third layer: $215.000 \mathrm{~m}^{2}=€ 13975 \mathrm{M}$

- Total: =€ $44481 \mathrm{M}$

\subsection{The effectiveness and replicability of the proposed solutions}

DRIVE 0 will demonstrate the effectiveness and replicability of the project's results by seven small scale demonstration projects, showing evidence of the effectiveness of the solutions to the involved stakeholders in the seven selected regions/countries as well as the effectiveness of finding and using specific drivers. DRIVE 0 will contribute to an increased rate of renovation in the residential sector by using a fully enduser oriented approach, supported by user centred business models. An endorsement and further exploitation of results is ensured by collaboration with consortium partners Housing Europe, with a replication and implementation of the projects' outcomes to 44 national and regional federations which together gather about 43000 public, social and cooperative housing providers in 23 countries, managing over 26 million homes, about $11 \%$ of existing dwellings in the EU and UIPI (the International Union of Property Owners) with a replication and implementation of the projects' outcomes to 28 national associations in 27 countries.

Table 3. Reduction of the carbon dioxide emissions (in $\mathrm{tCO}_{2}$-eq/year) triggered by DRIVE 0

\begin{tabular}{|c|c|c|c|c|}
\hline Country & $\begin{array}{c}\mathrm{CO}_{2} \\
\text { emission } \\
\text { before } \\
\text { renovation } \\
\left(\mathrm{kg} / \mathrm{m}^{2} \mathrm{a}\right)\end{array}$ & \begin{tabular}{|c|} 
Percentage \\
of $\mathrm{CO}_{2}$ \\
emission \\
saving by \\
renovation \\
\end{tabular} & $\begin{array}{c}\mathrm{CO}_{2} \\
\text { emission } \\
\text { after deep } \\
\text { renovation } \\
\left(\mathrm{kg} / \mathrm{m}^{2} \mathrm{a}\right)\end{array}$ & $\begin{array}{l}\text { Amount } \\
\text { of primary } \\
\text { saving by } \\
\text { renovation } \\
\left(\mathrm{t}_{\mathrm{CO} 2}-\mathrm{eq} / \mathrm{a}\right)\end{array}$ \\
\hline NL phase 1 & \multirow{2}{*}{51} & \multirow{2}{*}{90} & \multirow{2}{*}{5.1} & 21 \\
\hline NL phase 2 & & & & 8262 \\
\hline ES phase 1 & \multirow{2}{*}{59} & \multirow{2}{*}{87} & \multirow{2}{*}{7.7} & 16 \\
\hline ES phase 2 & & & & 5749 \\
\hline IR phase 1 & \multirow{2}{*}{76} & \multirow{2}{*}{80} & \multirow{2}{*}{15.2} & 13 \\
\hline IR phase 2 & & & & 134 \\
\hline IT phase 1 & \multirow{2}{*}{51} & \multirow{2}{*}{70} & \multirow{2}{*}{15.3} & 17 \\
\hline IT phase 2 & & & & 88 \\
\hline EE phase 1 & \multirow{2}{*}{50} & \multirow{2}{*}{70} & \multirow{2}{*}{15} & 62 \\
\hline EE phase 2 & & & & 5250 \\
\hline SI phase 1 & \multirow{2}{*}{88} & \multirow{2}{*}{75} & \multirow{2}{*}{22} & 33 \\
\hline SI phase 2 & & & & 992 \\
\hline GR phase 1 & \multirow{2}{*}{99} & \multirow{2}{*}{65} & \multirow{2}{*}{34.7} & 14 \\
\hline GR phase 2 & & & & 193 \\
\hline Total & & & & 20868 \\
\hline
\end{tabular}

\section{Discussion}

The challenge of DRIVE 0 is to turn identified barriers into chances and business opportunities, using the potential of specific and local drivers. Regarding the current barriers, these can roughly be distinguished in social barriers, institutional barriers, specific business barriers and industrial barriers:

- There is a general lack of knowledge about the scale and reasons for deviations from the goals of energy, indoor environment quality, health and well-being [1820], as well as a solid quality and moisture safety control [21-23] of the renovation process. To minimise cost of failures fully qualified and equipped workforce should be used, combining and implementing the quality checking procedure. The requirements and information about real building performance on energy, indoor environmental quality, health and wellbeing in relation to the renovation should be understandable and personalized to designers, constructors as well end-users/consumers.

- No proper methodologies to assess energy, durability and moisture safety performances of new innovative circular products and concepts. Indicators for measuring product's circular performance [24] should be transfer from processing industry to construction industry and assessment of service life and durability should be an important aspect in designing and constructing the circular renovation solution [25].

- A very important is the question how to assess and reward 'soft measures' in energy performance standards/calculations, measures like user awareness, training and education of users, provisions for predictive maintenance and performance control, continuously information and user feedback on energy behaviour, that are often very effective but are not rewarded in EP regulations and causes the energy performance gap [26-28]. The energy simulation model should be calibrated based on pre-renovation measurement of indoor climate, building performance, and energy use. Indoor climate and energy simulations should be done using the different user profiles:

- using the real user for optimizing the renovation solution taking into account that [29]:

- usage of DHW without circulation and the usage of household electricity do not change after renovation,

- there could be a major increase in indoor temperature and DHW energy use in buildings that did not have circulation before the renovation,

- there could be a small increase in the use of electricity in common areas was,

- using the standard user for calculating the energy performance certificate.

\section{Conclusion}

The overall aim of DRIVE 0 is to come to a decarbonisation of the EU building stock and to accelerate deep renovation processes by enhancing a consumer centred circular renovation process in order to make deep renovation more attractive for consumers and investors, environmentally friendly and cost effective.

Ready to use circular plug \& play prefab renovation solutions for the seven demonstration cases produced by 
fully automated prefabricating production lines (factories). The selected cases are already in preparation and each of these cases have a specific local driver for the need of a holistic and circular deep renovation, which is translated in 'case specific challenges and tasks' and case specific key performance indicators

This research was supported by the European Commission through the H2020 projects DRIVE0 (grant No. 841850) and Finest Twins (grant No. 856602), by Estonian Centre of Excellence in Zero Energy and Resource Efficient Smart Buildings and Districts, ZEBE (grant No. 2014-2020.4.01.150016), and by the Estonian Research Council (grant No. PRG483).

\section{References}

1. EPBD, Official Journal of the European Union L153, 13 (2010)

2. K. Kuusk and T. Kalamees, Energy Procedia 78, 985 (2015)

3. T. Kalamees, A. Lupišek, O. C. Mørck, A. Borodinecs, M. Aalmeida, R. Rovers, P. O. 't Veld, K. Kuusk, and S. Silva, in Central Europe Towards Sustainable Building 2016: Innovations for Sustainable Future, CESB 2016 (22-24.06.2016 Prague, Czech Republic, 2016), pp. 137-144

4. K. Kuusk and T. Kalamees, Building Research and Information 44, 1 (2016)

5. M. Padula, F. Picenni, R. Malvezzi, L. Laghi, J. M. S. Lissén, F. J. S. De La Flor, C. Mateo-Cecilia, L. Soto-Francés, M. N. Assimakopoulos, and T. Karlessi, TECHNE - Journal of Technology for Architecture and Environment 1, 127 (2018)

6. K. Mjörnell, A. Boss, M. Lindahl, and S. Molnar, Sustainability 6, 4227 (2014)

7. K. Kuusk, T. Kalamees, and P. Pihelo, in CLIMA 2016 - 12th REHVA World Congress, edited by P. K. Heiselberg (Aalborg University, Department of Civil Engineering, 22-25 May 2016, Aalborg, Denmark, 2016)

8. N. Barmparesos, D. Papadaki, M. Karalis, K. Fameliari, and M. N. Assimakopoulos, Energies 12, (2019)

9. S. Ilomets, K. Kuusk, L. Paap, E. Arumägi, and T. Kalamees, Journal of Civil Engineering and Management 23, 96 (2017)

10. P. Pihelo, T. Kalamees, and K. Kuusk, Energy Procedia 132, 1006 (2017)

11. A. Ferrante, A. Fotopoulou, G. Semprini, D. Cantelli, S. Ruggiero, M. Karalis, C. Efthymiou, D. Papadaki, and M. N. Assimakopoulos, in IOP Conference Series: Materials Science and Engineering (Institute of Physics Publishing, 2019)

12. A. Lupisek, K. Sojková, M. Volf, and P. Hejtmánek, in IOP Conference Series: Earth and Environmental Science (Institute of Physics Publishing, 2019)

13. S. D’Oca, A. Ferrante, C. Ferrer, R. Pernetti, A. Gralka, R. Sebastian, and P. op 't Veld, Buildings
8, 174 (2018)

14. K. Kuusk and T. Kalamees, Energy Procedia 96, 628 (2016)

15. A. Hamburg and T. Kalamees, Energy and Buildings 199, 332 (2019)

16. A. Hamburg, K. Kuusk, A. Mikola, and T. Kalamees, Energy 194, 116874 (2019)

17. S. Cozza, J. Chambers, and M. K. Patel, Energy Policy 111085 (2019)

18. S. Zuhaib, R. Manton, C. Griffin, M. Hajdukiewicz, M. M. Keane, and J. Goggins, Building and Environment 139, 69 (2018)

19. T. Prasauskas, D. Martuzevicius, T. Kalamees, K. Kuusk, V. Leivo, and U. Haverinen-Shaughnessy, Energy Procedia 96, 253 (2016)

20. Á. Broderick, M. Byrne, S. Armstrong, J. Sheahan, and A. M. Coggins, Building and Environment 122, 126 (2017)

21. P. Pihelo and T. Kalamees, Wood Material Science \& Engineering 1 (2019)

22. A. Kamenders, K. Kass, E. Biseniece, L. Lupkina, and J. Bazbauers, Energy Procedia 147, 636 (2018)

23. K. Kuusk, J. Kurnitski, and T. Kalamees, Energy Procedia 132, (2017)

24. S. Cayzer, P. Griffiths, and V. Beghetto, International Journal of Sustainable Engineering 10, 289 (2017)

25. K. Bourke and B. Kyle, Canadian Journal of Civil Engineering 46, 1074 (2019)

26. P. X. W. Zou, X. Xu, J. Sanjayan, and J. Wang, Energy and Buildings 178, 165 (2018)

27. M. Herrando, D. Cambra, M. Navarro, L. de la Cruz, G. Millán, and I. Zabalza, Energy Conversion and Management 125, 141 (2016)

28. P. van den Brom, A. Meijer, and H. Visscher, Building Research \& Information 46, 54 (2018)

29. A. Hamburg and T. Kalamees, Energies 11, 3179 (2018) 